\title{
ERRATUM
}

\section{CONNECTING RANDOM MATRIX AND TOPOLOGICAL LG MODELS VIA INTEGRABILITY}

\author{
[Mod. Phys. Lett. A, Vol. 6, No. 31 (1991) 2837-2842] \\ K. HERZIG, M. WEISSGOLD and P. TATARU-MIHAI
}

The correct spelling of the third author should be P. Tataru-Mihai. 